5-1-2011

\title{
Youth at the Nexus: Ideology in HIV Prevention in Nairobi, Kenya
}

\author{
Zohra Ahmed \\ Assistant Professor University of Georgia School of Law, zohra.ahmed@uga.edu
}

p bepress

\section{Repository Citation}

Zohra Ahmed, Youth at the Nexus: Ideology in HIV Prevention in Nairobi, Kenya, 11 Sex Educ. 129 (2011), Available at: https://digitalcommons.law.uga.edu/fac_artchop/1353

This Article is brought to you for free and open access by the Faculty Scholarship at Digital Commons @ University of Georgia School of Law. It has been accepted for inclusion in Scholarly Works by an authorized administrator of Digital Commons @ University of Georgia School of Law. Please share how you have benefited from this access For more information, please contact tstriepe@uga.edu. 


\title{
Youth at the nexus: ideology in HIV prevention in Nairobi, Kenya
}

\author{
Zohra Ahmed* \\ School of Law, Fordham University, New York, USA
}

\begin{abstract}
In the fight against HIV/AIDS, the Behavior Change Communication (BCC) model stands as international best practice in preventive education. Ideally, a BCC intervention aims to changes behaviors and attitudes by facilitating group negotiation and introspection, with a resultant improvement in health. However, introducing this best practice model to a group of youth in Nairobi resulted in suboptimal outcomes: they were unaccustomed to expressing themselves in the ways prescribed by the class. To explain this failure, I examine how local discourses produced by parents and teachers communicate agency, sexuality and health, and highlight the diverging practices invoked at home, school and by the BCC model to make these youth 'health conscious'. At home and at school, the key commonality was the absence of any attempt to inculcate internal reasoning - in contrast to the BCC model. Rather, they relied on external pressures, through repetition, silence and behavioral discipline. Both local prevention schemes operated according to their own coherent ideological framework, molded by structural circumstances. Given the contextual contingency of how agency is acquired and construed, a BCC intervention may undermine overall efficiency and the host community's cultural autonomy. Ethnographic analysis is needed to enhance our understanding of local schemes and their merits, and to envision more hybrid notions of agency mediating the global and local.
\end{abstract}

\section{Introduction}

For over 20 years, the scourge of HIV has captured the world's attention in guises tragically poignant and discontinuous. The acronym not only denotes the attachment of a retrovirus to immune cells, but also invokes an entire medley of images, facts and social agitation - shaping the decisions of those at risk, concerned citizens and global agencies trying to curb infection. In sub-Saharan Africa, in particular, there has been no shortage of conferences convened and commitments made to address the disease as well as the socioeconomic and cultural factors deemed to predispose the population to risky behavior. Initiated for the most part by non-governmental and supranational humanitarian agencies, these interventions work by disseminating authoritative recommendations for personal health and security from disease. Specifically, when the issue is the risk of young people contracting HIV, the roles played by parenting, pedagogy and the media have been scrutinized as the preponderant cultural factors shaping this risk and have subsequently been targeted for numerous reforms.

In the ethnographic research described in this paper, pedagogic approaches for effective prevention advocated by global health agencies, such as UNAIDS, the World Health Organization (WHO) and Population Services International, are contrasted with two local approaches implemented in the homes and at a school frequented by a youth

*Email: zahmed@alumni.upenn.edu 
community on the outskirts of Nairobi, Kenya. The lens used for this three-part comparison - between the school, the home and the international best practice - focuses on how each stakeholder uses its authority to perform HIV prevention (whether or not they consciously use the term 'HIV prevention' to frame their practices), and the subsequent values and messages communicated to the young persons.

Currently, HIV prevalence is highest in Kenya's urban areas at $14.3 \%$, disproportionately affecting the youth and women, both generally less empowered to take measures for their health. Still, the rate at which people have been infected has been declining since the pandemic's onset, due to the aggressive prevention reforms instituted at schools (UNAIDS 2008). As such, understanding local efforts as they evolve is imperative if global healthprevention strategies are to remain relevant. This three-fold comparison will make apparent the merits of local approaches in relation to the presuppositions underlying the type of model for health education, known as Behavior Change Communication (BCC), relied upon by global health organizations.

The type of subject envisioned by the global health agencies is founded on ideals of universal human rights and democratic citizenship, which is neither wholly compatible with the self-image of the young people in this Nairobi community, nor the methods their local authority figures use to teach prevention. Although local schemes differ, both parents and teachers externally condition preventive behaviors by relying on fear, reinforcement and deterrence. The external environment sets boundaries for preventive behavior. However, the theory underscoring the strengths of the global health model for education views the methods applied locally with skepticism; instead, internal change is encouraged through the development of internal critical faculties that would induce behavior change.

By gaining insights into the ideologies of these three stakeholders, their constraints and capabilities, this research attempts to identify the divergent notions of agency and health proposed to young persons at the local and global levels. Moreover, it also suggests that the content, mode of dissemination and social environment of prevention deserve more consideration when scrutinizing local prevention efforts. Finally, if no prevention scheme is completely right, how do we move forward without falling into the trap of cultural imposition on one hand and paralysis from over-thinking on the other? This is the primary concern guiding this inquiry.

\section{Methodology}

I first visited Kenya in summer 2005 and came upon the Cheleta Primary School within walking distance of my host's home in the outskirts of Nairobi. An initial meeting with the headmaster, followed by conversations with the head teacher, extended a spontaneous visit to the school into a longer term involvement over three consecutive summers. Offering to teach, I was assigned to mathematics, English and creative arts classes at different grade levels, on different days of the week. Although the language of instruction is English, except for the Swahili class, my ability to engage students increased with grade level because their English improved, and because those who were struggling in the language had left school.

Concurrent with teaching, I observed behind-the-scenes activities at a BCC health education intervention being implemented by an international non-governmental organization (NGO) at a local public secondary school in central Nairobi, which I discovered through an umbrella NGO that coordinates the disparate HIV-related efforts throughout the city. This institution was interested in trying a similar intervention at Cheleta, and with my help, a six-week pilot health education class was held the following year. As the 
pilot class unfolded, I conducted a first round of interviews with students and the chosen peer educators to understand their perceptions of the program. The following and final summer I conducted 76 structured interviews to extend my sample and corroborate findings. I followed up with these same students, and other students at the school, to inquire into their attitudes towards their own sexuality and HIVAIDS, their social and romantic behaviors, how sex and HIV had been presented to them at home, how they thought HIV could be prevented, and their attitudes towards these stakeholders in their health. I also interviewed these same students' school teachers, parents and community members to assess how, as authority figures, they addressed the health threat of HIV. I also interviewed government officials in the municipal education department and the central AIDS body.

With teachers and government officials, I investigated how each dealt with HIV prevention in theory and in practice. With parents and the members of their residential community, the interviews centered on my informants' sexual histories, relationships with peers, parents, other authorities participating in shaping their life's trajectories, and how they as individuals internalized the risk of HIV. I also gained insights into their parenting approach, their opinions on the best way to prevent HIV at home and at school, the factors informing their approach, and how they actually managed the health and sexuality of their adolescents.

Through interviews and informal conversations, the crux of three ideologies was reconstructed and with it the active modalities of power that internally organize the school, the home and the global health agencies. The themes extracted to illustrate the stance of each stakeholder are those that occurred most frequently in participant observations and interviews. Coding transcripts to rank the most prominent traits introduced a level of rigor to an endeavor designed primarily to get behind infection statistics and examine the mythologies of HIV/AIDS. However, assigning experience-distant terms and applying sweeping thematic brush strokes from a collection of conversations presents its own challenges, despite best attempts to ensure that the views noted reflect the social, political and community conditions of the area in which the study took place, rather than an essentialization of my informants. Nonetheless, having begun this research as an (uninformed) acceptor of the global health agencies' model for education, this is also a personal account that chronicles the realizations of a practitioner converted into an ethnographer in the field, relying on an anthropological analysis of these circumstances to define the challenges of preventing HIV infection ethically and efficiently.

The social nature of HIV infection makes a strong case for the social sciences' involvement in prevention. Although qualitative methods are not as conclusive as the results of "pure' sciences, they are: "sometimes a long way ahead of "scientific" evidence that moves politicians, donors and multilateral organizations ... [the] time lag between significant anecdote and quantitative "evidence" may be as long as 20 years' (Barnett and Whiteside 2003, 237). The strength of ethnographic methods lies precisely in its ability to raise questions, opening new avenues of critical inquiry and forcing innovation.

Ethnography, in particular, provides an opportunity to unveil the chosen context of dissemination, its performance and content, which in combination illustrate how subjects are formed to combat the risk of HIV, and to identify the morals, ethics and values that each stakeholder appeals to. Qualitative methods help to showcase the diverse occasions and the assorted discursive formations that contribute to the construction of infection prevention. Focusing only on what is said about HIV would constitute an error of omission. In so doing, ethnographic analysis of discourse and ideology brings into focus an ethical dilemma - given that each concerned party argues for the authority of its approach, what criteria should be used to determine where to place emphasis and allocate resources? 
The ethnography's methodological imports carry a risk because several factors could undermine the authenticity of my informants' responses. First, as a teacher in the classroom, I held a position of authority; outside the classroom, however, the barriers came down in our interactions because of the proximity of our ages. Nevertheless, the power imbalance is likely to have made them less forthcoming. The school was also my point of entry into my research, and so provides a more complete insight into the ideology of prevention, relative to what I can say about their households. Second, due to the sensitive nature of the topic, students and my other informants had an incentive to lie to me to maintain their privacy. Third, as a Pakistani female with a noticeable American accent, my otherness interfered with my ability to conduct interviews because I interviewed a selfselecting group of students and Githogoro residents open to a female foreigner asking questions about sexuality, and in English, no less, although I had the services of a translator. Lastly, the reader should be aware that the results of this research are joint constructions by ethnographer and informant (Briggs 1986). For example, when asking whether my interlocutor actively worried about HIV, I inherently presuppose and then perhaps draw out a concern about the virus. Interviews quoted should be treated as instances of social communication, rather than 'solipsistic confession' (Briggs 1986, 2).

\section{Ecosystem}

Kenya was colonized by the Germans in 1885, followed by the British East Africa Company in 1888. Nairobi was chosen as the capital, offering a cooler refuge, safe from the lowlands' propensity for malaria. Under the system of direct rule, white settlers occupied the highlands hospitable to agriculture, and gradually expanded their governance over the colonial administration. After decades of struggle, the Kikuyu who suffered the most from the settlers' landholdings organized in opposition to white rule, eventually establishing a movement for independence. After Independence in 1963, Nairobi experienced rapid urbanization, pushing agricultural plantations further north. Today, Nairobi is the metropolis for the greater East African region. Multinational corporations, government offices and the second largest United Nations compound are all concentrated in Nairobi, with Kibera and Mathare - slums infamous for their densely populated quarters. The country faces many challenges, notably corruption, political violence, poverty and disease. HIV prevalence has decreased from a level as high as $10 \%$ in the 1990s to approximately $8 \%$ today (WHO 2008). Faith-based organizations, local NGOs, government agencies, hospitals, international aid and agencies are all involved in pursuit of their shared goal. Kenya was cited for the second time in 2007 by UNAIDS as one of the few countries where the return on investment into HIV prevention was starting to show still the prevalence remains high (UNAIDS 2008, 41). One of the main challenges remains in increasing national ownership, sustainability and absorptive capacity, as $98 \%$ of currently available HIV funding is off-budget, accounted for by international donors (UNAIDS 2008, 3).

The field site is located in the eastern corner of Nairobi; in the early twentieth century, the British took control of this previously Kikuyu-held land for growing coffee. Locals were recruited as laborers for the plantations and their children attended the Cheleta Primary School, which is the school featured in this research. By the 1970s, most plots of land were developed as the Runda Estate, an elite gated community, with margins and pockets of land left over for two informal settlements, Githogoro and Ruma.

As plantations were replaced with palatial homes, some residents of Githogoro and Ruma have been able to find employment in informal retail or domestic service, security, 
casual carpentry and construction, as required by more affluent neighbors. However, high unemployment and high rents in Githogoro and Runda make the free municipal public schools the only feasible route for social mobility for the young persons living there. Githogoro has a larger population, consisting of rows of corrugated steel shacks, bisected by a main alley lined with commercial stands. Ruma, in contrast, is a newer suburban slum in the valley of the Karura forest. Githogoro's peripheral location in relation to Nairobi's city center has allowed it to expand with little regulation, absorbing waves of the rural exodus into this relatively secure slum, reuniting all of Kenya's ethno-linguistic groups.

\section{Ecosystem as host to competing ideoscapes}

Within the field site there is an ecosystem, host to active stakeholders in the health of young persons, particularly the home and the school. The research entailed mapping the ideoscapes, the flow of different ideas (Appadurai 1990) circulating around the youth in question and regulating their sexual health. The insights gained into how prevention takes place differently in each social space reveal the internal dynamics of each, and the relationships existing between stakeholders.

The ecosystem is unique, but also encapsulates dynamics common to modern Kenyan society. For example, although the Cheleta Primary School is defined by its own particularities, it also illustrates how state schools and the State operate more generally in Kenya. It stands in for the State's presence - the youth's main contact with the formal sector. It coordinates most of their peer socialization, and distributes certifications of 'skill' levels, according to which jobs and professional status are gained. Similarly, Githogoro represents the young persons' household culture and class position in urban civil society.

The same linkage is possible in referring to the particular NGO involved at Cheleta, and its efforts, as a particular result of larger processes of globalization that have profoundly affected the field site. Specifically, the BCC intervention can be taken as an emblem of a global health industry, whose purpose is to devise public health strategies systematically for citizens and communities across the globe. This is not to suggest that there is a monolithic approach to HIV prevention promulgated and embodied homogeneously by development agencies; rather, it acknowledges that while there are local manifestations of the prevention model that are highly variable, they are part of a larger economy of social development which is global in its orientation and effects (Appadurai 1990; Toor 2000, 3). The scope and approach of these organizations - some faith-based, others secular - vary greatly. But from one prevention model, the BCC, we can extrapolate from its specifics its fundamental organizing principles, and from there draw certain conclusions about the network of global health organizations as a whole. As will be shown, the type of model reflects, in part, those qualities that can be extended to all endeavors which seek to improve global health, and, also, those within global health which are secular, grassroots and youth-oriented prevention efforts. By taking care to distinguish between elements of the prevention model that are inherent to the body of global health organizations and those that are only true of a segment of it, the aim is to avoid reifying the global health industry but to acknowledge and scrutinize a type of activity.

Through exposure and explicit instruction, parents, teachers and global health professionals nurture the community's youth. Despite some overlap in their strategies for prevention, each approach maintains distinct relations between the youth and the prevention administrators. Even if prevention content were identical, because the nature of the interaction is different in each social space, the impact on young persons varies accordingly. Besides any explicit discourse disseminated about HIV prevention, each 
space assigns a role for these young persons to perform - a student, an adolescent family member and a young person vulnerable to infection. Thus, relations established between youth and authority shape self-understanding, peer interactions and health-related behaviors.

Each apparatus authoring and authorizing its own prevention scheme has its own motivations and employs its own discursive frame when speaking about HIV/AIDS. The entire production of discourse and the practices that each apparatus adopts to condition the way the youth understand their bodies and sexual agency manifest the reproduction of the apparatus' authority. All knowledge about sex and health is cloaked in a particular ideological perspective. Moreover, the knowledge generated is prompted by a position of power; the generation of knowledge reinforces this power, which in turn strengthens knowledge, fueling a symbiotic and synergistic relationship. It would be wrong to construe power as purely repressive, since this view neglects to explain why power is accepted. Power is effective when it is exercised with finesse and tolerable when disguised (Foucault 1990). The task at hand therefore is not to wipe clean ideologically tinted lenses; rather, we need to insert new filters to see that ideology is always already there (Zizek 2008).

Ideology not only is a filter of one's worldview, social purpose and self-recognition, but has a material existence (Althusser 1970). In coordinating our gestures, dispositions and everyday practice, as well as orienting us towards a particular position in political economy, ideology is skin deep and pervasive. The way ideology is disseminated is also part of the overall ideology; for this reason, theory and practice operate dialectically there is no simple cause and effect between the two.

Although the agent has been subjected to ideology, she is also the subject of her own desires: she is shaped by her outside world but she also shapes it herself. She is both object and subject. As subject and agent, she can only understand herself, and 'be' herself according to the logic erected by the ideology (ideologies) that shaped her. On the other hand, she subscribes to the ideology only when it allows her to see herself as subject with agency, otherwise the ideology would have no effect - she becomes an ideological object when she identifies with the ideal that this ideology imagines (Althusser 1970). This paradoxical phenomenon which Judith Butler calls subjectivation obscures the very categories of resistance and agency we use to evaluate the individual's ability to operate in her world: ' $[\mathrm{t}]$ he very processes and conditions that secure a subject's subordination are also the means by which she becomes a self-conscious identity and agent' (Butler 1997 in Mahmood 2001, 210).

If agency is contingent on the form of the subjectivation, then any definitive standard of agency can be proposed, and no one way to see how agency impacts health can be definitively fixed. The youth incorporate a stock of 'prevention capital' that expands their sphere of sexual agency, imparting practical mastery. However, practical technical mastery is defined not only by the extent to which it fulfills its objective, but also by the manner in which it does so. For example, saying no to sex as one foreign stakeholder suggests may not be viable or sufficient in a society that values obedience and subtly managing one's sexuality. When we look at how these youth are complexly situated at the nexus of these mechanisms of control and animation, evaluating their prevention capital is difficult to accomplish. We must understand how the mind and body are synchronized to each other to together express volition. Effective prevention practices are contingent on how 'the good life' has been envisioned. The length of this observation does not allow one to gage whether in their lifetimes student $\mathrm{X}$ equipped with prevention capital A circumvents risk better than student $\mathrm{Y}$ who was reared in space which gave her 
prevention capital $\mathrm{B}$, therefore $\mathrm{X}$ is better than $\mathrm{Y}$, or $\mathrm{A}$ is healthier than $\mathrm{B}$, and so forth. Given this limitation and noting that judging healthy sexual behaviors requires a degree of relativism, we focus on representations and simulations surrounding HIV/AIDS and an inquiry into the values framing health and infection in this community and for this community. It soon becomes clear that HIV prevention is not merely a scientific and epidemiological concern, but provides wider insight into how agents work to change their surroundings and those of others. An inspection into different preventive schemes poses the question as to whether there can be an international best practice for preventive education, given that we cannot use a single measure of health against modes of subjectivity.

\section{Cheleta's approach}

The school's campus includes four rectangular concrete buildings around a courtyard, and an acre of uneven land behind, enough for a makeshift soccer field and room for students to play during recess and physical education class. The classrooms are in disrepair and overcrowded, without electricity and adornments to divert attention from the perforated door, dirty walls and uneven floors. Students arrived by 7:30, and left as late as 4:30 because of mandatory examination preparations beginning in their penultimate year. In the upper classes, six teachers taught six subjects for three grade levels, totaling a maximum of approximately 250 students. The master schedule included time for all subjects tested in the Kenya Certificate of Primary Education (KCPE) as well as physical education, creative arts and games and library study, but the classes for tested subjects often spilled over into the times allocated to the non-tested subjects.

In the upper primary classes, there was only one female teacher - for English. Teachers varied in age and experience, but the majority held long tenure. The two teachers most active in the lives of these upper primary students were also the deputy headmaster and the head teacher for the entire school. Both had been at Cheleta for four years. Only one of the six had a master's degree, the rest were high school graduates who had subsequently matriculated at teacher's college.

In the corner of each classroom is the teacher's table, which faces a sea of rickety desks, loosely arranged in rows and columns at the front of the classroom, but receding into an undifferentiated cluster where students share their desks. Stuffed into their newspaper-lined desks are their worn copybooks, pencils sharpened to their tail ends, remnants of ballpoint pens without their plastic casing and miscellaneous personal possessions. The students organize themselves in proximity to their social clique, with the highest achieving students sitting closest to the teacher's desk, and those struggling with English in the diagonally opposite corner. Illuminated by the natural light streaming through the large windows and rotting door, the students learn in obedient silence. Although teachers are expected to prepare lesson plans synthesizing various teaching aids and information, the government-issued textbooks guided their daily instruction. Internal examinations were set sporadically and with little notice. The teacher projects a loud assertive voice, syncopated to the flow of the argument or concept being presented. Interspersed in the lecture, the teacher would often pose directed questions that foreshadowed the correct answer, or add 'isn't it?' at the end of a sentence, to revive the students' flagging attention. Students responded in the affirmative 'Yeeeesss, teacher', as an immediate reflex. Class participation for the students takes the form of answering in chorus, emphasizing the teacher's singularity and the students' uniformity. Dominating over the rows of students, the teacher often paces the length of the blackboard and in the 
narrow passages between the desks. Students copied down the chalked paragraphs covering the entirety of the board, often identical to the paragraphs in their books. During this time, the teacher would sit at their desk grading homework or overseeing the students. Those students lagging hide behind a veil of repetition, following the chorale lead by the class' best students. When teachers could not elicit a clear answer, they would repeat and perhaps elaborate on the instruction, offering another chance. Rarely, however, were explanations provided to the below-average student.

The two teachers who were most active in the school were aware that their classrooms were deeply stratified, which is partly why they accepted me, eager to single out for me those students in most need of personalized coaching. They conducted an after-school tuition program for upper primary students needing to catch up, or revisit their persisting academic challenges. During these sessions, the pattern of question and response in chorale did not play out, since students were divided in achievement-based groups, benefiting in rotation from the teacher's help. Still, these teachers maintained firm authoritarian relations with their students. For example, absences or tardiness with tuition fee payments were causes for strict disciplinary measures.

The teachers noticeably amplified their voices for many of the lessons touching upon sex or HIV/AIDS. They directed more questions at their students, reverted to Swahili more frequently and made more deliberate efforts to ensure their audience was following in mind and spirit. The teachers delivered information about the disease's pathology, infection and social impact, charged with forceful concern: 'If you don't wash your hands, you will get sick.' 'If you have sex, you will be with HIV, and then you will no longer be able to help your family.' Punctuating these exhortations with questions, they would ask for the chorale to answer, 'What will happen if you don't ...?'

By governmental decree, HIV-prevention lessons have been integrated throughout the curriculum of primary and secondary schools in Kenya. Incorporating HIV into the various disciplines is thought to ensure accuracy and propagation, as this material was subject to examination. Teachers also taught Kenya's formal motto for prevention - ABC, or Abstinence, Be Faithful, use Condoms - but stressed Abstinence.

For example, in their English classes, students read a story about caring for those infected with HIV; whereas in social studies, the effects of the disease on society at large were discussed at length. In their science class, while learning about proper sanitation, they also learnt about HIV-transmission prevention; when discussing cell structure, information about what a virus is and how it affects the body was also conveyed. The integration of HIV into the curriculum represents another move towards a technical and practically-oriented primary education, a practice dating to colonization (Court in Uchendu 1979, 30). The curriculum aims to impart students with knowledge immediately useful in their surroundings. Rather than teaching students the scientific method, their science class equips them with technical information, about how to keep themselves healthy and how to better understand their natural environment in order to master it. Students are not being educated to be internationally competitive: they are not taught to think critically, nor given the necessary skills for problem solving.

With access to universal primary education guaranteed for all since 2004, in conjunction with a shift towards a more technical education, school prepares students for the lives that lie ahead of them. The resources available to them are just as scarce in school as outside; students receive almost no individual attention from teachers, and have limited access to learning materials and educational facilities. Moreover, their time in school even at the primary level serves as a basis for certification, rather than a milestone leading towards secondary education. There is little possibility of social mobility. Finishing 
primary school may be an accomplishment relative to their parents' achievements, but at the very best maintains these students' class positions (Court in Uchendu 1979; Cole 2004, 577).

As one upper primary school teacher noted:

these students need to be shown, they are not being taught how to act properly ... we wish we could make all of them be part of the class and pass their exams .... after [the] universal primary education [statute], every day, like this morning we have parents enrolling their children, we cannot turn them away ... this is why we don't mind you, these students need to feel special.

Failure to respect the order and standards of the classroom ensured a swift scolding or physical discipline. These scoldings, reported indirectly to me by both teachers and students, involved an interrogation into the reasons for the breach, and then any combination of accusations of 'bad behavior', 'poor discipline', 'stupidity', 'disrespect' and of being a 'chokorah' (garbage scavenger). Corporal discipline was administered every Friday for all those who stepped out of line during the week. Lined up, in the main courtyard, students waited to receive their measure of punishment from the school principal, who was otherwise absent from day-to-day activities at school.

Although physical discipline in schools has been banned in Kenya since 1999, the practice is widespread - Cheleta being no exception (Human Rights Watch 1999). The school operated under semi-formal standards: teachers were employed by the state, used state-issued teaching materials, and prepared their classes for the national examination marking the completion of primary education, KCPE. Still, the school's isolation and the weakness of the Kenyan state resulted in diminished accountability and direction.

With this distance, these teachers had license to overstep their formal roles. Besides using physical discipline, they also prescribed moral and health standards outside what was laid out in the state curriculum, effectively stepping into semi-parental roles. The teachers felt compelled to provide moral instruction to these students based on their impressions of these students' home environment. In the stories about what they knew of the students' home lives, the teachers reified a culture of poverty as the constant explanatory variable for their students' underachievement.

\section{Author's question: what is Githogoro like?}

Lower primary school teacher, residing on the premises:

You know, it is not that bad. Even myself I was surprised to find tomatoes there ... which is an expensive vegetable. But even now when we have the KCPE even some pregnant girls of sixteen come and take their exams. Their parents, many of them are doing prostitution, and don't care if their children come with torn uniforms ...

One lower primary teacher told me about a girl who repeatedly neglected her homework. When calling her aside for an explanation, she confessed that she could not work at home because her mother asked her to leave the house during the frequent trips made by her paying male visitors. After years of teaching, he related a Kikuyu proverb to illustrate the lesson learnt: 'the silent part of the river is the most dangerous'.

Many of the teachers felt they could decipher the red flags of moral lapses by the students or by others living with them. Still, their impressions of the students tended to inflate the extent of their sexual experimentation, relative to student estimates about their peers. In my research, I knew that eight students of the 52 in their penultimate year were sexually experienced. Despite their head-shaking at the thought of their pupils' active sexual lives, the head teacher and deputy headmaster saw themselves as agents of a 
gradual change. Since their arrival a few years ago, higher standards of discipline had been enforced, including reduced promiscuity, according to the two most active teachers. Positing a culture of poverty at home and its symptoms evident in the students' 'undisciplined behavior' provided a foil to make prominent their professional expertise and the import of their work.

In line with the official policy of encouraging abstinence first, teachers were explicit about discouraging any sexual activity in their student body. Abstinence was represented as the epitome of self-restraint and internal strength. On one occasion in a gendersegregated discussion scheduled specifically to discuss sex, the teacher lectured the female students: 'If you have sex, you can get pregnant, you can get HIV/AIDS and it is very, very bad ... Those boys, they will try to touch you and convince you, but stay away from those boys.' From their perspective, lack of physical and social contact would keep them out of harm's way. Teachers also put emphasis on the risk of sexual violence in line with their philosophy that sex education should cover all risks.

If they suspected sexual precocity, the teachers were persistent in extracting the truth. For example, when explicit letters were found detailing a romantic relationship between a schoolgirl and an anonymous boy, one of the new teachers relied on his previous experience as a counselor. After calling her aside, his questioning gradually yielded a penitent confession. She justified her indiscretion with a, ' . . . but, Sir, I'm not alone'. This led him to conduct a wider search, the results of which were presented as an implausibly precise estimate of the number of students that he believed were sexually active.

The teachers filtered what their students learned, and in so doing enforced a normative path for psycho-social development. In primary school, prevention information could not acknowledge the possibility of sexual activity. Acknowledging sexual activity and providing relevant prevention advice could be viewed as a license. One senior teacher discouraged the use of condoms, explaining that 'sexual education is taught in stages ... for primary students it is not appropriate to concede sexual activity'. In secondary school, he clarified, condoms could be discussed.

Regardless of what they were teaching, the teachers at Cheleta employed the deposition method of instruction in which 'the students are the depositories and the teacher the depositor' (Freire 1993, 34). Acknowledging their teachers' authority and expertise, students learned by memorization and repetition; only two to three students in each class appeared to fully assimilate the material, and demonstrated the ability to think critically about what they were learning. As a result of undifferentiated instruction, there was a visibly wide range of competencies and vocal participation in a single classroom.

Within their authoritarian pedagogy, fear was the mechanism used to deter these young persons from breaching the behavioral standards the teachers had set inside and outside the classroom. The combined use of fear, rehearsed knowledge, repeated implied threats and deposited sexual knowledge was designed to instill fear and psychological anxiety in these young persons about pre-marital sex and its potential repercussions. From the teachers' perspective, this anxiety was a strategy of defense they ingrained in the youth. Fear facilitates the youth's ethical capacities, making the path towards health straight and narrow, staying out of harm's way because of the agent's insurmountable and visceral fear of it.

The use of fear and the reliance on the deposition method are not choices made after having considered a rich array of pedagogic practices on offer, each of which they are fully familiar with. By their own admission, crowded classrooms left them little room to maneuver physically and pedagogically. The teachers were overwhelmed by the number of students and the enormous difficulties they faced on the job. Establishing order was the 
prerequisite for the school to function. The most active and interested teachers felt obliged to fill in for a lack of discipline in their students' home environments. Recognizing the long odds their students faced in making progress, teachers made sure that at least the inclination for obedience was well ingrained in their pupils, which they considered the most basic unit for behavior needed to climb the educational ladder, get ahead in life, and avoid the traps of poverty, especially HIV. On closer inspection, the teachers' authoritarian stance is a recuperative act, and a dissimulation of their institutional impotence. In a file on the school maintained at the City Council Annex, housed at the Chief Advisor of the School's offices, the official records documented a long narrative of internal disruptions and management irregularities. From the perspective of the state apparatus, the school stood as an egregious case of failure - for the past 10 years Cheleta has remained in the bottom tier of municipal rankings. Officials and teachers both confessed to me that this was no one's first choice for job placement. With no affordable housing in the estate, and without mention of the slum as a possible housing alternative, the tedious commute made 'teachers not motivated ... the teachers feel like a stranger in Runda Estate', recounted the Chief Advisor, echoing the same explanation for the students: 'Children will need a lot of encouragement because they will just look around ... Both pupils and teachers are visitors ... Runda is made of "very rich [who] don't want to dilute their standard of living".' Whereas students dutifully believed in the idea of the school as the path to social integration through formal certification, behind the walls of the office and staff room, the teachers' relationships with their peers and immediate supervisors were strained and unprofessional, evident in law suits and corruption allegations in the school's official file.

The combined result of these set of circumstances - the state's limitations, teachers' reified construction of the students' material and cultural impoverishment, the school's marginality and the insurmountable challenges faced by all players - helps explain why teachers teach the way they do. Their pedagogic tactics are heavily determined by the degree of structure at the school relative to the state's central institutions, and their monopoly of expertise relative to the students' parental culture. Still, the ideological practices are not guaranteed results of the school's structural position. Nonetheless, it is clear that any reform of the school's prevention practices will require a complete re-configuration in the material conditions within which its actors operate.

\section{Parental culture}

To draw out the community's social construction of HIV and its prevention, I relied on interviews with parents and community members. Of those who were not parents, most were young adults aged 21-30 who shared their perspectives on their own development through childhood and adolescence on issues of health, sexuality, romance and sexual and moral education they received. The young adults' perspectives addressed the question of 'what happens next?' when the students leave school, are more likely to be sexually active and can exercise greater agency.

Significant obstacles had to be overcome to get my informants to talk about HIV. Githogoro residents were not eager to speak about sexuality and HIV. The mood during these conversations was varied; few were indifferent and most were straight to the point and matter of fact.

Whenever I asked to be introduced to any HIV-positive individuals, my informants never knew exactly where they lived or how to reach them, although they acknowledged that there were residents who were sero-positive. Everyone cited rumors of people with 
HIV, but it seemed that none socialized with them, or they did not wish to tell me. The one woman with HIV my translator knew never left the house and refused visitors. Residents and students framed their assertions about these invisible victims based on their chronic illness, alienation from the community and perceptible physical weakness. From these subjective assessments of symptoms, rumors proliferated. Either those infected with HIV who resided in Githogoro did not rely on community support, or those who assisted these individuals did not divulge details.

Most residents were indifferent to or depreciatory about their physical location and their neighbors. Talking about what they thought about their environment and community inevitably moved the conversation towards the problems of Githogoro and 'village vices', as Steven, aged 22, put it to me. For Steven, 'village vices' were specifically drugs, liquor and changaa, the illegal brew produced in homes. Poverty and unemployment were invariably mentioned; a few parents mentioned the lack of access to good schools. These were the reasons given by my informants to explain various 'failures' in Githogoro society - school drop-outs, early pregnancies and prostitution. Those who had positive attitudes were the few locals who had grown up in Githogoro, and had established networks since childhood. Most residents were newcomers from rural areas, smaller towns or other parts of Nairobi. Their outlook towards their shared environment was strictly functionalist, a place that offered access to affordable housing and income-generating activities through small commerce:

most people have different behaviors which you learn how to deal with ... [you] have to accept it, don't say it's bad ... I can't change people's choice ... have to accept it. (Evelyn, aged 28)

I like Githogoro because I can get something ... I don't want to be social here, people have [been] born here, I just want to get money. (Janet, aged 29)

Informants' attitudes betrayed an underlying suspicion about their fellow community members. Frustrated with prevailing patterns of socialization or wary of investing effort in the community, it seemed that many residents retreated into their immediate concerns. Many lived in homes that would eventually be razed to make way for a road, most were tenants, most hoped to be able to leave for better surroundings. Within this moral universe, loitering in public spaces, such as the alleyways or the main thoroughfare, was cited as a sign of moral degeneracy. Instead of being at home, where one contributes to the household, loitering is associated with deviating from the integrating and wholesome functions of the family. For instance, many women pointed to evidence of bad behavior when children roamed Githogoro's thoroughfare without supervision or when adults wandered aimlessly.

Households and individuals valued their privacy and autonomy, although achieved with difficulty in the cramped quarters of the slum. Maturing into sexual agents in an environment where public places are strictly functional and community ethos is absent, pre-marital sexuality was a covert activity. Since it was unacceptable at home and in public, the nearby forest offered a private refuge for pre-marital romance. The normatively accepted path for romance in these young and older adult lives was a pattern of romantic courtship and sexual relations beginning in their late adolescence that often led to marriage. While this trajectory violated the widely accepted moral precepts of pre-marital abstinence, this emotional and sexual development was itself normative by virtue of its repetition. My informants who maintained that they had transgressed ethical-moral precepts they professed still stated that they had compromised their best interests by behaving immorally. 
In accounts of my informants' sexual histories, the work environment and then school were cited as the places where romantic and sexual interactions were initiated. Following initial introductions, sometimes followed by courtship where uncertainty and opacity kept the two partners at a distance, they would become a couple. No one had been in a relationship before marriage that had been endorsed by the parents. All romantic relationships were discrete and unacknowledged, unknown to or explicitly discouraged by authority figures. Marriage took place when it was no longer tenable to maintain the secrecy and lies otherwise required. Parents may not have approved of their marriage choices, but informants said their spouses were eventually accepted.

Sara, aged 24, had to lie to her parents, telling them that she was visiting her cousins to allow her to go to Mombasa with her boyfriend, now husband. Her parents strongly disapproved of her pre-marital sexual relations, but she remarked, 'what can they do to stop me?' They eventually expelled her from the house when they found out. Soon after, she married her husband. 'Now they [her parents] approve.'

Few had resisted pre-marital sex, and those who did cited strong religious beliefs or deep-seated myths: Holidah, aged 33, said she learned in social studies not to play with boys and said, 'my sister told me that if boys touch your breasts you get your menses'. This kept her away from her male peers in school. Pre-marital sex was not accepted in any household, nor had a single person planned for his or her first sexual encounter. No one cited condom use. The few who took preventive measures got tested with their partner at a Voluntary Testing Clinic.

For the most part, younger and more educated parents were more likely to bring up the issue of HIV and sex with their children, these mentions taking the form of a lecture. Only a few parents made the connection between household discussions about sexuality and the health of the children. Evelyn, aged 28, asserted: 'it's a big problem, parents don't monitor [youth] ... don't understand what this love means'. When I asked her to elaborate, she told me: 'Parents don't talk to their children about sex because they fear that their children will think that their parents are bad ... they don't want their children to know what happened to them.' For the most part, fathers said that they could not discuss sexual matters with their daughters. For Maxwell, aged 21, the age of 12 was the right time for his daughter to know about sex: 'As a father, you can't talk to your girl ... it doesn't create a good picture.' Other fathers of current Cheleta students echoed this same concern for propriety. Mothers expressed their fear and shame when talking to their children about sex, unwilling to have their own trespasses unveiled to their children. Moreover, many were resigned to the fact that they could not explicitly teach their children how to manage their sexuality in a safe way, but just warn them. As a Cheleta father indicated to me, comparing his sexual development with that of his children: 'By that time, it was very simple, you can trust people'. He remarked, 'sex, you can't teach - very difficult, they will learn just the way you do'. When sex and HIV were brought up in the students' homes, they were not in discussion but a one-way communication intended to establish the rules for behavior. In many cases, these sermons included thinly veiled threats of the punishment upon discovery of sexual activity.

When parents were forced to face the issue of their adolescents engaging in sexual activity, many confessed to a lack of control over their behaviors. Certain parents expelled their older children from the house and others, resigned to reality, urged their children to 'just stick to one'. The preventive measure advocated by Christian parents, the majority of my informants, was to inculcate faith in God and Jesus, who would keep their children out of harm's way. 
From young adults' reflections on their own upbringing and from descriptions of current students' parents, households overwhelmingly opted to put the burden of health education on the school and the church. However, parents were unaware of how prevention was taught at school, and did not know in any detail the effort invested there to try to re-orient students' behavior. A minority of adults had completed secondary education and therefore emphasized the value of education for their children, believing that higher academic achievements would translate into socio-economic advancement, and better health. My informants never attributed knowledge about the virus as a factor decreasing one's risk for HIV.

My informants articulated their views on the disease by relying on a moral and material framework. Across the board, HIV/AIDS was the result of 'bad behavior'. Individuals with HIV were not, however, inherently prone to 'bad behavior', nor could it be solely attributed to personal choice. 'Bad behavior' resulted from events and circumstances outside the individual's control. Poverty inclined individuals to a greater risk of HIV, as did exposure to films depicting romantic or sexual scenes. A lack of fear of God was another cited predisposition for infection. Exposure to the ways of the city was also likely to encourage errant ways. Hetero-socialization, the 'lack of discipline' of city dwellers and the ubiquity of television were noted as features of urban life that explained why individuals contracted infection. After his experience teaching HIV prevention in school, John noticed that 'people in the city have more sex and are less disciplined'. Responses highlighted the interplay balance between social and psychological forces to account for why certain people had HIV. They expressed sympathy for victims but stressed the need for self-reliance, an expectation that resonates with the realities of Githogoro's unfamiliar community network, leaving residents with nothing to fall back on other than themselves.

It is evident that no single outlook or scheme of prevention prevails in Githogoro. Parents and community members stratified by education level, experiences and origins engage youth sexuality in different ways. Moreover, the processes of urbanization and globalization are changing local stakeholders' HIV-prevention methods, suggesting the impermanence of certain features of this segment of parental culture. Additionally, generational differences were evident by how the virus' social impact and its prevention were articulated. Given their own experiences as maturing persons in a time when more is known about HIV/AIDS, and more is being communicated about curbing transmission through billboards, the media and schools, the new generation of adults and parents were deciding which elements to discard from their upbringing and which elements to introduce in rearing the next generation, particularly in regards to sex and health.

In contrast to the school, in Githogoro prevention is based on habituated exposure to ongoings in the household and in the residential commons. Although explicit messages are delivered, these young persons are expected to conform to what they understand it is to be proper, and to avoid or keep private whatever is omitted in conversation and in action. Furthermore, parents did not articulate a prevention scheme the way the school's teachers did.

Although sexuality and health were issues of concern for parents, parents did not list $\mathrm{HIV}$ as a primary concern for their children. An improvement in economic standing and moral rectitude of their children ranked higher on their list of parental concerns. Risk of exposure to HIV was seen to be a function of moral laxity and a precarious financial status. Similarly, prevention was seen to be part of child-rearing. Parents felt a lack of control over the infection and the social conditions that have allowed it to spread rapidly. Parents of all ages described how they did have sex before marriage, and their expressed regret. Although the norm of abstinence is subverted in practice, it is reinforced as a desirable 
norm in discourse. This paradigm affected how parents talked about sex at home; how young persons should actually behave to conduct themselves to avoid 'bad behavior' was not a feature of the household's prevention scheme. Moreover, discussing sexuality was itself seen to undermine standards of propriety and privacy. The practice of avoiding explicit discussions on matters of sexuality itself conditions a particular mode of sexual agency. The external silence and the disavowal from the public space erected a barrier of acceptability; as such, the exterior environment protects individuals from 'bad behavior'.

\section{Youth at the nexus}

The perspective of the young persons these stakeholders constantly keep in view now merits attention. In order of importance, students derived their knowledge about HIV/AIDS from their official curriculum, mass media, peers, and parents. Often in the language of their textbooks, students summarized the tragic irreversibility of HIV/AIDS while stressing the need to keep the hope for those infected. In effect, memorization of countless lectures and texts resulted in accurate and often sophisticated responses to questionnaires and to interviews, despite the poverty of knowledge and tools in the fundamental subjects. By repeating HIV-related knowledge across subjects, accurate information about HIV had been disseminated to Cheleta's students. The curricular HIVprevention program managed to avoid the fate of many instruction failures characterizing education at Cheleta. This remarkable success explains why Kenya has been commended for curbing infection through an aggressive awareness campaign aimed at delivering accurate information to its citizenship (UNAIDS 2008).

Students were uninformed about contraception besides abstinence and condom use. Less than 10 students out of 52 in their penultimate year could describe how male condoms were used; female condoms were unknown to them. Moreover, the relative risks of each mode of transmission were not well explained: students cited going to the barber or sharing needles just as frequently as they mentioned unprotected sex, although it seemed unlikely that they would be able to pay for a barber or intravenous drugs. Their discourse demonstrated a discomfort in talking about sex as a general practice; in contrast, they talked more easily about sexual scenarios deemed morally reprehensible. Indeed, prostitution and rape were cited as the riskiest of sexual events as opposed to consensual sex without protection. Unfortunately, the spectrum of actual sexual encounters that fall outside these categories of 'dangerous sex' was not elaborated upon.

Students attached a stigma to the disease: contracting the disease was not just an unfortunate fact of biology but a dreadful, preventable outcome of immoral choices. Moreover, despite their awareness of its fatal consequences, students could not imagine how HIV could actually impinge on their own lives. Although AIDS was a reality in their community, they demonstrated little curiosity as to how individuals got infected. Even when students claimed to know someone with the infection, they could not tell me who these persons specifically were, nor venture to guess how these people may have contracted the disease. Students were aware of the moral panic surrounding AIDS, repeating maxims from their elders and the media about the devastation it caused and the dangerous behaviors it signified. Yet AIDS did not appear to enter the real logic of their everyday lives. Students conceived of AIDS in abstraction, as a social monster. The risk for HIV was not thought of in personal terms because it would imply moral deviance, and so the students detached themselves from the threat in their responses. Rather than seeing it embedded in the risk of certain interactions and circumstances, AIDS was thought of as an intangible but daunting threat. 
Ensconced in moral considerations, the prevention messages these young persons received were part of a larger process of education, of which health promotion was a part. Securing one's health amounted to securing one's morality; in other terms, one's moral standing measured one's preventive capital. Socializing mostly with one's own gender comprised the crucial component of acceptable behavior. As a result, students were safe so long as they remained within their gender group. Socializing with the other sex undermined one's virtues, because in those circumstances one's sexuality could be channeled into behaviors and thoughts increasing the risk of pre-marital sex. Hence, students preserved their morality by making a distinction in their behaviors between those of the same sex and those of opposite sex. In doing so, their socialization upheld the norm of heterosexuality, because sexuality could only lead to sex when in the company of the opposite sex. Additionally, morality was closely associated with the degree to which they respected the defined gender their sex assigned to them.

Female students were more aware of managing their sexuality according to these assumptions and values. Although their male counterparts also remained more closely affiliated with their gendered group, it appeared as though the young women took the initial steps to secure this divide. As a consequence, male students felt that they were being rejected by their female peers as unworthy of their attention.

My young informants all professed to preserve the standard of chastity expected of them. If a rare student did admit to having a romantic partner, and no one else did, this person would often divulge other people's secret affairs, alleviating personal shame and normalizing their own choices. Exposure or disclosure of sexual or romantic involvements was deemed to be undignified.

By their final year, by my count, eight out of 52 students had engaged in sexual intercourse. Only three maintained ongoing sexual activities; those no longer sexually active explained their behavior as a mistake, and expressed remorse. The majority of students at the end of primary school at an average age of 15 had abstained. Although sexual activity is not prevalent in primary school at this age, information from young adults in Githogoro, who are part of the same generation but older, suggest that these young persons may engage in premarital sex later in their lives.

Numbers aside, an internalized sense of respectability and fear of trespassing the dominant sexual code was widespread. In interviews, students expressed their prospects for the future in relation to how well they satisfied the demands of being a student, a member of a household, and a moral and virtuous member of society.

\section{Safeguarding global health}

One of the insights gained from the tableau of local prevention schemes is that personal health is entrenched in socio-cultural realities and their symbolisms. Having reached similar conclusions empirically, a group of organizations dedicated to global public health has proposed models for prevention education that aim to influence the psycho-social aspects of health.

The notion that HIV must be systematically prevented in Africa is accepted wisdom to many inhabitants of our globally interconnected planet. To acknowledge this duty towards distant others, an entire moral project had to unfold, beginning with the declaration of universal human rights in 1948 and the human rights charter which outlines a set of basic human entitlements. It is institutionalized compassion, and its principles demand an adequate response to human suffering, and provide a code of ethics for a cosmopolitan world. This particular articulation of human decency enshrines citizens' demands for 
democratic governance and engenders the development of liberal democracy (Gearty 2006, 43).

The belief in human rights requires a leap of faith. The evidence for inalienable rights is sparse - it is not DNA encoded, nor is there a single adequate response to human suffering, nor only one road to tolerance. The ambiguity of the human rights framework most salient to the issue at hand is whether the right to health overrides the right to cultural autonomy and whether models said to be universally applicable in the fight to save lives undermine communities' ability to solve their problems.

Overlooking these ambiguities, human rights provides the ideological springboard for the project of development, in which the efforts of HIV prevention are included. Understanding the issue of AIDS in Kenya to be the result of local and external forces and therefore a shared responsibility, divisions of the United Nations and international nongovernmental agencies have launched HIV prevention efforts across the country. The morbidity, anxiety and societal debilitation that HIV inflicts are seen as a violation of the human rights discourse's utopist expectations. As the founding principles of global public health initiatives, this ideology permeates the form and content of its interventions. As the war against suffering is waged, these agencies have imagined a globally legitimate order that frames the Third World's problems, delivers a measure of worth and progress, and sets the stage for development (Ferguson 2007, 16). The global order provides a lens through which to view the problems in specific areas as part of a generalized trend, which therefore mandates a generalized solution. However, the global model of development based on the satisfaction of universal human rights obscures local realities, desires and nuances in the ways problems can be solved (Ferguson 2007, 23).

To uphold the universal right to health, institutions of international development such as the United Nations, WHO, Family Health International, International Federation of Red Cross and Red Crescent Societies and Population Services International all take part in delivering healthcare in countries where access and methods are insufficient. These organizations vary in how they go about securing health in impoverished countries and in the scale and range of their activities but they operate based on a common humanitarian motivation towards improving the life conditions of the global community, particularly those members who cannot do so for themselves. There are many health education models for the innumerable classroom programs across the globe which seek to change behaviors and reduce risk for HIV. Within the typology of health education programs, one important subset can be identified: this type of program subscribes to a socially dynamic view of health, and a secular 'rights-based' approach to development; that is, rather than concentrating on the needs of people, projects focus on the rights of people as a measure of sustainability (UNESCO 2008, 15). Also, although these organizations carry out their activities on a global scale, they all originate from western industrialized nations. BCC is but one of the formal titles accorded to this type of health education program by UNAIDS, Family Health International, USAID and Population Services International (Family Health International 2002; Population Services International 2007). Other names have been coined such as Information, Education and Communication or Communication for Social Change. These programs can encompass not just class-based prevention education but all types of efforts, whether through personal interaction or mass-media campaigns, which try to alter behaviors through effective communication, with the goal of tackling a wide array of social problems - such as infection, addiction, conflict resolution and domestic violence. BCC was the specific name used by the agency implementing the health education class. BCC in this instance refers to the BCC-modeled health education 
class, and will serve as the model to ground the ideological inquiry into the types of approaches employed by a group of global health agencies.

By creating the appropriate pedagogic arrangements through a $\mathrm{BCC}$ intervention, issues concerning health are addressed by replicating the kind of social environment deemed necessary for health promotion. The small classroom creates a microcosm for the ideal society, in which human rights and democratic negotiation are its cardinal features. Most importantly, the class aims to alter how people think about their individual welfare and the welfare of community members, and how they act within this context to enhance the realization of their needs and rights. In so doing, these prevention classes introduce a different discourse framing the problem of HIV, and hence an entirely different ideological practice producing HIV-free subjects. Discussing sexuality and HIV in 'judgment-free space' is the essential procedure for teaching HIV prevention in a class environment, according to the global health organizations recommending BCC-type programs.

A BCC implementation ideally develops over several stages. The exact number depends on the level of detail contained in organizations' literature - Family Health International delineates up to 12 . For this analysis, four stages have been used to highlight the essential concepts and approaches of the model. First, those leading the effort must reach into the larger community in which they plan to be working. They must gain the trust of these stakeholders, take into consideration their opinions and concerns regarding HIV and the sexual health of young persons, and maintain an open dialogue throughout the intervention. Second, the curriculum is crafted by members of the agency with appropriate localization of lesson plans; a health education class, for example, incorporates village elders as part of the teaching group to uphold the customs and preferences of the community and the young persons in the class. The curriculum is then revealed to the peer educators who will lead the classroom; often these are young persons in the community who are older than the students, have leadership experience and demonstrated commitment to their community and heightened HIV awareness. These peer educators are trained to facilitate discussions, and adjust the lesson plans to their needs. Peer educators work under the supervision of the intervention specialists and teachers, and their degree of autonomy varies. Third, the class is conducted, mostly on a weekly basis. Fourth, and ideally concurrently with the third stage, the class is subject to evaluations by those attending and the stakeholders. The curriculum and overall approach are refined on the basis of the feedback, as the intervention matures, continues and expands (Family Health International 2002).

BCC's curriculum builds upon itself and prides itself on being holistic in content and form. Before broaching the topic of HIV or even sex, students learn about the foundations of relationships, whether romantic, familial or platonic. Discussion and interactive activities are the chosen mechanisms to disseminate information and stimulate thought. A topic is introduced and questions are asked to improve critical thinking: students are then expected to take the lead while the peer educators guide them towards internal reflection and group negotiation. Having reflected upon these issues, having had the experience of making 'responsible' choices and having received formal training, the peer educators introduce responsible and beneficial standards throughout the discussions. They are meant to represent an inconspicuous authority figure, providing non-threatening guidance (Visser 2004).

The class's success is measured by how fruitful the conversations are and by the quality of the evidence for potential behavior and attitude change. If students get to a point where they actively investigate the various ways they could expose themselves to infection, think 
of ways of protecting themselves and each other, and commit to acting upon these new insights, then behaviors are likely to change in the interest of greater health.

'Participatory', 'student centered', 'interactive' and 'problem solving oriented' are the terms that describe BCC's type of classroom and, by no coincidence, pedagogic best practice for practitioners and educational theorists. This pedagogic best practice applies to any subject matter and any age group. Features of this pedagogic best practice are incorporated and are replacing older approaches to teaching and learning, in institutions across the globe. Since a BCC program anticipates a relatively small class size, and starts from scratch, the $\mathrm{BCC}$ can capture all the elements of this best practice.

The practice of discussing and then re-negotiating attitudes and behaviors relevant to why HIV spreads in a group forum takes its cue from a larger paradigm central to current thinking in global health. Interventions have drifted away from a biomedical orientation towards policies that place emphasis on the community impact on the individual's psychosocial development and health, and vice versa (Beecker et al. 1998; Tawil et al. 1995): health depends on how the individual is being told to be healthy, how much she has assimilated, whether she is inclined to act on this information, how specifically she intends to do so, and whether she has enough agency in her social context to do so. This view of health has now become orthodoxy, and has been translated in two ways when it comes to preventing HIV. First, the models for health education promoted by global health agencies try to create group environments and dynamics that are believed to be most successful in changing behaviors and attitudes (these also happen to be environments where the individual's autonomy is best safeguarded). Second, it has motivated research and outreach in the communities where these health education programs take place.

In the end, the successful BCC program alleviates the risk of HIV, and strives to uphold human rights. To carry out this larger vision, the implementation must mobilize social capital (Campbell and Jovchelovitch 2000; Kreuter 1997). Social capital broadly refers to one's access to social networks and one's standing within them. Social capital is important for health promotion, because communities that are rich in social capital provide a supportive context within which people can collectively re-negotiate social identities in ways that promote the increased likelihood of health-enhancing behaviors (Campbell and Jovchelovitch 2000, 6). As such, one of a BCC's aims is to build stronger social networks, so as to enable the kind of dialogue and change it envisions.

There is a synergistic relationship between dialog and social capital: social capital creates the chance for dialog and the eventual satisfaction of human rights; dialog also strengthens interpersonal connections and builds social capital. When those involved are able to reach out to each other by participating in discussion, trusting relationships can be forged, and new behavioral patterns set. Dialog therefore does not just entail talking; it improves if each participant is active and their point of view is given due consideration. The persons in a prevention scheme need to be able to talk to each other face to face, without feeling pressure to say what is expected of them, and be open to others' views. At the same time, there need to be clear guidelines as to the objectives of the discussion and the standards to be used to arrive at newly negotiated practices and attitudes. In a very deliberate fashion, the health education classroom becomes a site for democratic negotiation, the results of which are regulated by the principles of human rights.

Additionally, the acquisition of life skills is essential in an effective health education program. In that spirit, theater and skits provide a stage for students to try out their new identities and test their community's reaction through performance. The capacity to debate with peers, share opinions and arrive at consensus is also an important skill imparted in the 
BCC, which has value in real-life relationships, particularly in deciding when to have sex, and use protection (Mabala and Allen 2002).

Discussion, dialog and performance serve as the external mechanisms to create the conditions for behavior change. Internal changes must occur in parallel for these group activities to be effective. To explain the kinds of internal changes needed for inter-group dialog to be furthered and for health education to result in behavior change, Catherine Campbell provides an account, relying on Paulo Freire's writings. Campbell, a leader in the field of HIV-prevention programs in youth communities in sub-Saharan Africa, has theorized extensively on why intervention programs such as BCC are crucial to the fight against HIV. Most health education programs do not have a deliberate Freirian approach to teaching. Nonetheless, the BCC shares the same holistic vision as Freiran critical pedagogy, seeing one's risk for HIV as a part of a larger interaction between psycho-social forces. The framework Campbell relies on differs only semantically from other conceptual frameworks explaining the merits of BCC-type models (see Family Health International 2002 for differences).

According to Campbell, BCC-type programs must aim to cultivate critical consciousness, so that the marginalized agent can attempt to overcome the forces of structural violence, manifested as poverty, infection and gender inequality, by recognizing the sources of their oppression and altering their behaviors accordingly (Campbell and Jovchelovitch 2000). The goal of health education is to create the conditions for the individual to transcend the stage of 'intransitive thought':

where people believe that control over their lives is out of their hands and ... do not see their own actions as capable of changing their conditions. God or luck are seen as the way out of

their often very poor living conditions. (Campbell and Jovchelovitch 2000, 4)

With the recognition that the individual has control over their health, livelihood and welfare, the individual, through the support of the group, undergoes conscientization. Conscientization refers to a 'dynamic relationship between critical thought and critical actions triggered by the ability to think holistically and critically about one's condition' (Campbell and Jovchelovitch 2000, 4; Freire 1993).

To achieve conscientization in a classroom, student-teacher relations are equalized, introspection replaces memorization, and knowledge is generated by consensus (Campbell and Foulis 2002). Therefore, preventing HIV is just one of the benefits claimed by a classroom committed to the BCC model; its participants are supposed to become critically thinking and acting agents in all spheres of life. Ultimately, and ideally, the BCC aims to induce 'culture change', by reconfiguring gender norms, sexuality and psychology (Campbell and Foulis 2002; Mabala and Allen 2002; UNAIDS 2008).

\section{Global models in local practice}

When I participated in the implementation of a BCC class at Cheleta, students had difficulties responding to the peer educators' questions, whether in English or Swahili. Neither the topics suggested nor the preferences voiced by parents and teachers, as extrapolated from preliminary research, nor the pre-existing lesson plan crafted by the NGO, could draw out the open conversation that BCC aims to generate. Students were mistrustful of one another, and did not feel comfortable expressing themselves freely, thwarting attempts to engage in discussion. Moreover, students repeated the responses they were expected or taught to give to questions concerning pre-marital sex, or the risk of HIV/AIDS. Even in gender-segregated discussions, particularly amongst the females, 
students were not comfortable to talk about romance, sex or sexually transmitted infections. When certain classes were dedicated to theater and skits, the more academically oriented students still took charge, delegating roles and dictating the plot lines. Most students were reluctant to playact any of the imagined characters who compromised normative standards of morality and respectability. After eight weeks of the pilot intervention, little progress could be seen. Students did not take the class seriously without the threat of punishment, which would belie the goal of the class. Despite efforts to bring the group together, few students ventured out of what they had learnt in class and at home about sex and HIV.

In effect, these adolescents had been accustomed to a certain discourse around these issues, and to their role in being privy to this discourse. To summarize, the comparison between local and global prevention schemes stands clearly as a series of contrasts, respectively:

(i) The external environment directly erects the safeguarding limits for sexual behavior as opposed to the creation of an external environment to help facilitate internal checks for healthy behavior.

(ii) Reliance on fear and repetition as opposed to reason as the mechanism to translate messages into behavior change.

(iii) Hierarchical relations between stakeholder and youth as opposed to equalized relationships.

(iv) Threat and silence versus dialogue and verbalization as the mode of dissemination.

(v) Abstracted construction of HIV as opposed to personalized and anecdotal construction of HIV through theater and transmission of life skills.

The evident disjuncture between global health theory and local practice deserves consideration. To a certain extent, the initial challenges of the pilot intervention are discussed in BCC literature. Authors such as Campbell and McKay, expert in health education, suggest that such obstacles are symptoms of marginality or an unfortunate result of being subjected to education couched in 'ideological dominance or controversy' (McKay 1998, 134). These frictions are deemed temporarily necessary, a sign of overcoming the stage of 'intransitive thought' (Campbell and Foulis 2002). Eventually, the students are meant to conform to the BCC's standards of communication. But can such endurance be ethically maintained?

In reading the students' behaviors as a sign of their marginality, rather than seeing them as an equal but distinct alternative mode of creating a healthy lifestyle, the BCC makes larger assumptions about what constitutes the good life. But how can we be sure that we are not misinterpreting cultural differences as a sign of inadequacy?

The agencies promoting BCC programs are confident about the suitability of their healthpromotion strategy to be universally normative and applicable. The local prevention schemes need to change precisely because they are deficient in the qualities the BCC program embodies. Essentially, the BCC type of classroom extends a critique of the type of teaching that takes place at Cheleta, and the way sexuality is managed in Githogoro households which are 'ideologically tainted' impediments to free expression (Campbell and Williams 1999, 26; McKay 1998, 134).

The regime of discipline at school and the regime of silence at home are understood to thwart individual agency, because one is still a dependent subject and not an independent agent. The BCC philosophy views these obscurities and silences as repressive, impeding true knowledge and control over one's circumstances. Essentially, in this line of thought, the local strategies of prevention reflect the community's economic marginality, and 
accordingly must be enhanced and improved upon. The BCC program would deliver liberation, measuring one's agency as a transcendence of or trespass against custom and heteronomy, which are equated with oppression. The global health model posits agency and health-promoting behaviors as overt and independent resistance to the kind of authority and pressures ingrained at Cheleta and in its students' homes.

The fundamental source of divergence and dispute between the global solution and local adaptations is in the distinct constructions of authenticity at play. The BCC's pedagogic approach assumes that authenticity - that is, being true to oneself - cannot be rehearsed or externally systematized. In other words, because the school and the home do not talk about sexuality with the deliberate objective of making young persons independent, rational thinkers, their prevention scheme does not suffice. Respect for the participants' individual autonomy and independence is one of the grounding healthcare ethics of BCC intervention, because it is the basis for enhanced agency. Agency from this point of view means believing one is free, believing one knows best, believing one has control and then actually realizing these wishes without restrictions. However, such a vision draws upon ideals rooted in western liberal traditions and hence not necessarily universal (Duncan 2002, 140).

In truth, agency, resistance and the ability to effect change - in the broadest sense of the terms - vary in form and content across space and time (Mahmood 2001, 207). As Saba Mahmood reminds us:

[...] [if] the ability to effect change in the world and in oneself is historically and culturally specific (both in terms of what constitutes 'change' and the capacity by which it is effected), then its meaning and sense cannot be fixed a priori ... one that must be understood in the context of the discourses and structures of subordination that create the conditions of its enactment. (Mahmood 2001, 212)

Mahmood's ideas suggest that we need to show restraint in critiquing local prevention efforts and the resultant effect on young persons' subjectivity just because they fail to satisfy a particular ethical standard, and fail to take a certain form. For example, as Mahmood elucidates, western feminist movements often describe the agency they wish to popularize as one in which women rebel against the norms defining their societal role. This is almost taken to be accepted wisdom nowadays in political movements. In other contexts, submission could secure power and equality for women, as Mahmood demonstrates in current urban Egyptian society.

Accordingly, criticisms directed against sexual education strategies because they are ideologically tainted or controversial neglect to consider the tensions underlying democratic liberal health education, and its own ideological underpinnings. Other traditions such as paternalism could also be a viable ethic to shape healthcare, as suggested by the teachers' attitudes at the school. As such, searching for a universal pedagogic model for protecting young people against HIV may be the wrong objective.

We must interpret what takes place locally in local context. Granted, the youth cannot choose their parents or their schools, and do not have a basis for comparison. We cannot say that they have willfully submitted themselves to 'these structures of subordination' (Mahmood 2001, 212). Nonetheless, their fear of HIV and docility towards their teachers, parents and the sovereign sexual norms do not have to be incapacitating. Nor is repetition of moral precepts necessarily superficial. Similarly, agentive capacity is not bound to the negation of power, and therefore neither is sexual agency nor health contingent on undermining prevailing methods used to prevent sexually transmitted infection. It is thus plausible to interpret youth submission to discipline as a strategy for their selfpreservation, and something which could be built upon, rather than eliminated. 
Saying no out loud may be a quick way to staying healthy, but perhaps local preferences for subtlety also have their merits. Re-enacting the precepts of abstinence and living in fear of HIV and avoiding whatever behaviors parents have remained silent on could also be powerful ways to cultivate one's interior disposition for healthy sexuality.

Local schemes could equally be the source of inspiration for prevention schemes, once their ideological practices and forms of agency are deconstructed, and their meanings unveiled. It requires placing the pedagogic practices and the resulting youth behaviors in their own comprehensive framework. But fundamentally, as demonstrated by ethnographic accounts, the local schemes challenge the fundamental conceptions of what is ethical and good, and the physical form these constructions take. Teachers, parents and NGO practitioners may all agree that abstinence is the best strategy for prevention for youth of this age. Indeed, the young persons may profess this same standard as well. But the way in which one goes about being healthy is the crucial distinction at play.

These nuances that define what it means to be one's 'true' authentic self remain unacknowledged in the BCC literature. The BCC model affects a kind of cultural override. A particular mode of expression, based in western liberal thought, is promoted as universally applicable, as a natural point of arrival when one progresses from being unhealthy to healthy, and when the standard of living improves. Effectively, the change envisioned by the BCC program is not contained within one corner of social life - it calls for capacious, cultural change. When health education tries to re-orient the way one thinks and social interactions, it enters the political sphere (Duncan 2002). Once the accurate biomedical facts have been attended to, practitioners have to decide what is normative, proper, or best suited for a 'good life'. In deciding on their core healthcare ethics and project outcomes, how clear are BCC practitioners about the nature and worth of their desired outcomes? Given the wide breadth of a BCC project, practitioners need to be clear about the frictions their agenda poses to local values and ethics, and at what (local) cost their project is being pursued. Besides undermining community autonomy, could a BCC implementation be less efficacious than a more localized intervention?

To a certain extent, global health agencies are conscious of the ethical complexity of their task. Practitioners seek a reasonable balance whereby cultural identity, community autonomy and health are safeguarded. The balancing act preoccupies many reflective practitioners in the field of global health, Campbell included, from which has emerged a prolific body of literature to ensure rigorous attention to local values and social networks. From experience, practitioners stress that the real experts are those who reside in the communities they are serving (Maurer and Kelly 2005, 50).

However, despite a stated intent to collaborate as equals with the local communities, global humanitarian agencies supporting BCC programs or organizations have significant advantages that tilt the scales in favor of their approach. Their interventions receive relatively consistent funding and their development strategies are crafted by members of the western academic community and thereby considered scientifically objective. One of the consequences of this advantage is that even when community participation is deemed central to improved health outcomes, local knowledge and practices are seen to be relevant only to the extent that they service the intervention's aims. This is a trend that has been documented across the globe, shaping the interactions of global health agencies and local communities (Butt 2005; Pigg 2001; Briggs 2003). The consequences of implementing a $\mathrm{BCC}$ for local agendas receive little attention.

Furthermore, there is little discussion in the development literature on what constitutes local identity, or who local experts might be despite their central role. As this ethnography makes apparent, local realities are not defined by static cultural practices, but carved out by 
power, institutional legacies and change over time. The task of choosing which parts of local identity to preserve for participatory prevention schemes raises another set of complex issues. For instance, the deliberate and self-conscious choices the individual makes to live everyday life are just as important as the unconscious reflexes she may not control, but which still determine her way of life. Although the BCC strives to embody democratic education, as a grassroots intervention proposed by outsiders of the community, its respect for community autonomy and self-governance is limited by a more urgent motivation to change behaviors, enhance health, secure human rights and protect individual autonomy.

The cultural override the BCC calls for is necessary given its goals, motivations and origins. Inherently, as a sexuality education intervention, the BCC tries to change something in the local community. It must weigh certain concerns and values over others, and remain steadfast to the notion that more healthy sexual behaviors provide a gateway to enhanced welfare.

The claims drawn here against $\mathrm{BCC}$ practices aim to push the envelope for prevention efforts, and introduce a bioethical perspective to sexual education by pointing out the moral ethical complexity of creating a BCC health intervention. Paying attention to the bioethics of the intervention goes beyond seeking permission from the local community, and requires charting out the values espoused by the project, and the potential conflicts that may ensue.

Clearly, only paying heed to local schemes would replicate the inequalities and failures evident in the realities of Cheleta and Githogoro. Still, it is difficult to separate which parts of their ideological practices are inadequate for health promotion or merely different until we pay more attention to the complexities carving out the 'local'. Inherently, any attempts to reform local schemes will require institutional and structural changes, given the force of these material and historical forces impacting the way HIV is taught differentially across social spaces - an insight which re-affirms widely-held wisdom that reduced HIV infection rates are best achieved through systemic poverty reduction.

\section{Conclusion}

This comparative study of pedagogic and child-rearing approaches employed by local and global stakeholders hopes to offer a critical re-appraisal of which standards to set when evaluating HIV prevention schemes. In so doing, a fundamental paradigm of globalization surfaces - a balancing act between universality and local particularities. Local identities and practices operate dialectically with notions of universal, 'natural' rights. Claims made to preserve local culture can weaken universal claims of right and wrong, and when universal human rights are invoked in particular instances, these claims can undercut ongoing local processes. The best HIV-prevention model must mediate between these two contested spaces.

Without a doubt, the participatory ideals underlying the BCC approach are commendable, and preventive education is sorely needed. Still, the theory and assumptions guiding its application impose a culturally specific measure of authenticity and overlook other possible ethical frameworks. By highlighting the frictions global health policy presents to the advancement of local agendas, adaptations and modes of expression, we can hope to balance the approach taken by certain global health agencies. To properly understand the local level, we need to investigate local institutions and their structural positions, since prevention is always ensconced in broader practices of subject formation. 
Responding adequately and ethically to HIV will require a more plural perspective. Dispelling belief in a singular, a priori setting for producing healthy persons, efforts must be made to identify the diverse types and forms of democracy, agency and rights across space and time. The gravest error would be misreading cultural difference as material inadequacy - a re-establishment of oppressive legacies. To avoid this, the point of departure for future efforts must rest firmly in the local, in all its complexities.

\section{References}

Althusser, L. 1970. Ideology and ideological apparatus: Notes towards investigation. In Lenin and philosophy and other essays, 129-88. Trans. Ben Brewster. New York: Monthly Review Press.

Appadurai, A. 1990. Disjuncture and difference in the global cultural economy. Public Culture 2, no. 2: 1-24.

Barnett, T., and T. Whiteside. 2002. AIDS in the twenty-first century: Disease and globalization. Basingstoke: Palgrave Macmillan.

Beecker, C., C. Guenther Gray, and A. Raj. 1998. Community empowerment paradigm drift and the primary prevention of HIV/AIDS. Social Science and Medicine 46, no. 7: 831-42.

Briggs, C. 1986. Learning how to ask. Cambridge: Cambridge University Press.

Briggs, C. 2003. Why nation-states and journalists can't teach people to be healthy: Power and pragmatic miscalculation in public discourses on health. Medical Anthropology Quarterly 17, no. 3: 287-321.

Butt, L. 2005. 'Lipstick girls' and 'fallen women': AIDS and conspiratorial thinking in Papua, Indonesia. Cultural Anthropology 20, no. 3: 412-42.

Campbell, C., and C.-A. Foulis. 2002. Creating contexts that support youth-led HIV prevention in schools. Society in Transition 33, no. 2: 339-56.

Campbell, C., and S. Jovchelovitch. 2000. Health, community and development: Towards a social psychology of participation. London: LSE Research Online. http://eprints.lse.ac.uk/2587.

Campbell, C., and B. Williams. 1999. Beyond the biomedical and behavioural: Towards an integrated approach to HIV prevention in the Southern African mining industry. Social Science \& Medicine 48, no. 11: 1625-39.

Cole, J. 2004. Fresh contact in Tamatave, Madagascar: Sex, money, and intergenerational transformation. American Ethnologist 31, no. 4: 573-88.

Duncan, P. 2002. Values, obligations and 'good lives': How useful is bioethics to sex educators? Sex Education: Sexuality, Society and Learning 2, no. 2: 133-44.

Family Health International. 2002. Behavior change communication (BCC) of HIV/AIDS: A strategic framework. http://www2.unescobkk.org/hivaids/FullTextDB/aspUploadFiles/bccs trategy.pdf (accessed January 22, 2008).

Ferguson, J. 2007. Global shadows: Africa in the neo-liberal world order. Chapel Hill, NC: Duke University Press.

Foucault, M. 1990. The history of sexuality. Trans. Robert Hurley. New York: Vintage Books.

Freire, P. 1993. Pedagogy of the oppressed. New York: Routledge.

Gearty, C. 2006. Can human rights survive? Cambridge: Cambridge University Press.

Human Rights Watch. 1999. Kenya spare the child corporal punishment in Kenyan schools, 11, 6A. http://www.hrw.org/legacy/reports/1999/kenya/index.htm.

Kreuter, M. 1997. National level assessment of community health promotion using indicators of social capital. WHO/EURO Working Group Report.

Mabala, R., and K.B. Allen. 2002. Participatory action research on HIV/AIDS through a popular theatre approach in Tanzania. Evaluation and Program Planning 25, no. 4: 333-9.

Mahmood, S. 2001. Feminist theory, embodiment, and the docile agent: Some reflections on the Egyptian Islamic revival. Cultural Anthropology 16, no. 2: 202-36.

Maurer, L., and M. Kelly. 2005. Lessons learned and global partnerships. American Journal of Sexuality Education 1, no. 1: 39-50.

McKay, A. 1998. Sexual ideology and schooling: Towards democratic sexuality education. London, ON: Althouse Press.

Pigg, S.L. 2001. Languages of sex and AIDS in Nepal: Notes on the social production of commensurability. Cultural Anthropology 16, no. 4: 481-541. 
Population Services International. 2007. Behavior change communication. http://www.psi.org/ our_programs/products/bcc.html (accessed January 23, 2009).

Tawil, O., A. Verster, and K. O'Reilly. 1995. Enabling approaches for HIV/AIDS promotion: Can we modify the environment and minimise the risk? AIDS 9, no. 12: 1299-306.

Toor, S. 2000. Indo-Chic: The cultural politics of consumption in post-liberalization India. SOAS Literary Review 2, July. http://www.soas.ac.uk/soaslit/issue2/TOOR.PDF (accessed January 22, 2009).

Uchendu, V.C., ed. 1979. Education and politics in Tropical Africa. Edison, NJ: Transaction Publishers.

UNAIDS (Joint United Nations Programme on HIV/AIDS). 2008. Kenya. Country situation. http:// data.unaids.org/pub/FactSheet/2008/sa08_ken_en.pdf (accessed January 20, 2009).

UNESCO (United Nations Educational, Scientific and Cultural Organization). 2008. Educaids Technical Brief. http://unesdoc.unesco.org/images/0015/001584/158436E.pdf (accessed January 22, 2009).

Visser, M.J. 2004. Implementing peer support in schools: Using a theoretical framework in action research. Journal of Community \& Applied Social Psychology 14, no. 6: 436-54.

WHO (World Health Organization). 2008. Epidemiological fact sheet on HIV and AIDS - Core data on epidemiology and response. Working Group on Global STI and HIV/AIDS Surveillance. http://www.who.int/globalatlas/predefinedReports/EFS2008/full/EFS2008_KE.pdf (accessed January 22, 2009).

Zizek, S. 2008. Talk presented at the Brecht forum, April 12, in New York. 
Copyright of Sex Education is the property of Routledge and its content may not be copied or emailed to multiple sites or posted to a listserv without the copyright holder's express written permission. However, users may print, download, or email articles for individual use. 